\title{
How to Build It So They Come: Using THE INTERRELATIONSHIP QUALITY FUNCTION Deployment Matrix to Design a Professional Business Student Club
}

\author{
Nate Luciano, Mary Bolo-Blum, \\ Tyler Lokietek, and Lisa M. Walters
}

A web appendix for this paper is available at:

http://dx.doi.org/10.15239/j.brcacadje.2016.05.01.wa04

Lisa M. Walters is corresponding author.

Nate Luciano

Senior Management Major

Mary Bolo-Burr

Master's Program, Interdisciplinary Studies

Tyler Lokietek

Senior Management Major

Lisa M. Walters

Assistant Professor, Operations Management

The State University of New York-Fredonia 
76 The BRC Academy Journal of Education Vol. 5, No. 1

Fredonia, NY

\begin{abstract}
This case study focuses on how the operational tool of interrelationship matrix of Quality Function Deployment (QFD) tool was used by a group of operations management students to design an on-campus branch of a national professional organization, specifically the American Society for Quality (ASQ). To develop the QFD interrelationship matrix, secondary research was conducted to establish the Voice of the Customer $(\mathrm{VoC})$ requirements in terms of potential future employers of business students. Because these requirements were derived from secondary sources, the weights of the importance of the requirements were considered uniform, as the research sources did not identify emphasis of any one requirement in preference of another. Primary research was also conducted by use of a business student focus group to identify the types of activities students would find desirable, thereby encouraging their alignment with the ASQ student group. Such activities constituted the design requirements of the group. These requirements were further weighted by the focus group and correlated to the $\mathrm{VoC}$ requirements to determine the specific student group activities that would be most advantageous to facilitate future employment opportunities for business students. The two key pursuits identified through the QFD process were live consulting projects and technical workshops. The results are useful for advisors and leaders of professionally-linked student groups in any profession as well as university career development offices.
\end{abstract}

Keywords: operations management, quality function deployment, student groups, employability, critical thinking, retention, ASQ, interrelationship matrix

\title{
INTRODUCTION
}

Student activities and groups are a part of collegiate life. Students are able to establish relationships and engage in activities that make their 
lives richer and their collegiate experience that much more memorable with varied group goals. Groups differ in their goals and activities, providing a virtual banquet to students interested in participating. At The State University of New York-Fredonia, 172 student groups are currently formally recognized, representing the spectrum of intents, from athletics to academics.

However, do these student groups provide any tangible benefit to the student while in school? And does membership provide further benefit to the student in terms of employability? This study seeks to determine how to design a student group that facilitates such benefits.

\section{LITERATURE REVIEW}

The role of student groups in a student's educational life has not been the subject of significant research on the whole. In past few years there has been some research on dynamics of small group impact on student development (Gellin, 2003); fewer studies have focused on retention and marketability (Astin, 1984) (Lotkowski et al., 2004). However, some work is available on the subject, and this body of work, as discussed below, suggests that student groups indeed offer positive outcomes to students. The focus of this research is on the role of student groups in facilitating student success beyond a student's academic career.

The work of Lotkowski et al. (2004) focuses on methods to facilitate student retention. The study assessed various aspects of student life, both academic and non-academic, in an effort to understand the factors that influence student retention. The study suggests academic self-confidence and achievement-orientation have the strongest relationship to college grade point average (GPA). In addition, the study indicates even students who perform well academically may still be at risk of dropping out of college, suggesting that a focus on academic performance as a means to retention is inherently flawed. As a result, the role of non-academic issues, such as confidence and motivation, play a key role in retention. 
Such aspects may be bolstered by student groups if the student groups are designed to provide opportunities to develop confidence and secure achievements.

Two works, by Peter D. Hart Research, Inc. (2006) and Tugend (2013), suggest an on-going gap between employer needs and the skillset of business graduates. Peter D. Hart Research, Inc. (2006) study found that $63 \%$ of business executives believed a majority of college graduates were not equipped with the skills necessary to be successful in the global economy, particularly in terms of teamwork and problem-solving. Tugend (2013) indicates employers felt skills involving writing, speaking, adaptability, prioritizing, decision-making, and problem-solving are lacking. Tugend (2013) further indicates that although new graduates are skilled technically, they lack the ability to put those skills into practice in the real-world business environment. Germane to this skill set is the ability to think critically.

A meta-analysis by Gellin (2003) looked at the previous decade's studies to determine the effect of various aspects of life, including student groups, on the development of critical thinking within students. Critical thinking is imperative to the problem-solving and decision-making skills necessary to be successful in the modern business environment. Gellin (2003) establishes that clubs and groups, including overall campus life, have a significant positive effect on the development of critical thinking, highlighting the work of Tsui (1998) that provided the most significant insight into the positive effects of clubs and societies in terms of critical thinking. Gellin's conclusions suggest that students who live on campus and participate in clubs and societies that involve significant social interaction show increased levels of critical thinking over their peers. The club or society activities that result in the largest benefit remain unidentified within the study, suggesting that critical thinking improvements from involvement with clubs and societies stems from the increased social interaction which facilitates stronger commitment to the organization (Astin, 1984). This notion of increased 
social interaction implies a larger exposure by the student to varying opinions and perspectives from within the group. Thus, a student group that engages its members will enhance a student's social interactions which can improve his or her marketability and career success.

While the literature available on the benefits of student groups is minimal, the research available suggests that not only does a group membership foster positive outcome for students, but it may also fill the gaps the employers find lacking in graduates (Gellin, 2003) (Tsui, 1998). To accomplish this goal, it makes sense that the activities of such a club must not only address the needs of potential employers (Peter D. Hart Research, Inc., 2006) (Tugend, 2013), but also the interests of the students, facilitating the social interaction necessary to benefit student retention (Lotkowski et al., 2004) and critical thinking development (Tsui, 1998). An industry tool that relates the needs of the customer to the design of a process, product, or service is Quality Function Deployment (QFD). This tool has also been applied in academic settings in a variety of applications, including the design of kindergartens (Moura e Sa and Saraiva, 2001), the improvement of secondary education academic experiences (Bedi and Sharma, 2006a), the development of business case studies (Bedi and Sharma 2006b), and the establishment of a governance system within a higher education system (Hafeez and Mazour, 2011). These applications are further discussed below.

QFD was developed by Yoji Akao (1972). Its essential purpose is to provide a tool to ensure the critical requirements of the customer, known as the Voice of the Customer $(\mathrm{VoC})$ requirements, are effectively addressed by a product or service design (Akao, 1994). Essentially, it is a tool for listening to the VoC. QFD requires four pieces of information (Ross, 1988). First, it is essential to know what is important to the customer (the "what's"). Second, how those important requirements can be met in the product or process must be established (the "how's"). Third, the relationship between the "what's" and the "how's" must be determined. Lastly, the emphasis of the "how's" is identified; that is, how much of the 
"how's" must be provided by a product or service to address the "what's;" this emphasis is known as the "how much."

QFD is associated with a variety of techniques. One such technique predominantly used in QFD is the House of Quality (HoQ), a matrix which not only utilizes the four pieces of information described in the preceding paragraph, but also seeks to understand the inter-relationships of the technical specifications as well as the benchmarks and targets for the technical specifications (Akao, 1972). However, the practice of QFD should not be associated solely with the HoQ, and practitioners are cautioned to use the techniques which will assist them in achieving their goals (http://www.qfdi.org/what_is_qfd/qfd_approaches.html). For example, Danilo Sirias (2012) developed an experiential learning activity to teach operations students QFD using only the interrelationship matrix of the HoQ in an effort to improve a business course. Thus, depending on the practitioner's needs, the approach to QFD may be diverse.

QFD has been used successfully in academic settings. Moura e Sa and Saraiva (2001) used QFD to determine what would be an ideal kindergarten from the stakeholders' view. This study was inspired by a need to become more responsive to educational expectations in the academic and socialization arenas. Researchers determined that a study for kindergartens was appropriate because attitudes toward education in general are largely determined by the kindergarten experience, and kindergartens tend to have more control over their policies, procedures, staff, and the physical environment. Moura e Sa and Saraiva (2001) collected opinions (voices) of the customers (parents, children, and teachers) from diverse circumstances. Specifically, these included personal experiences, feelings, and expectations of the customers which were then transformed into customer requirements. The researchers converted the requirements into characteristics of the target product, thereby designing a kindergarten curriculum which ensured all stakeholder voices were heard. 
Bedi and Sharma (2006a) applied the QFD concept to secondary education. They interviewed randomly selected students regarding their preferences in affecting better academic procedures at the school. The study focused entirely on curriculum, teachers, and examinations and asked how the school experience could be improved. Two schools supplied a random sample of students and rated the performance of the school on its ability to prepare them for standardized testing. The researchers hold that Quality Function Deployment (QFD) was effective in discerning which policies should be implemented to provide more satisfaction of students studying at the secondary level. Further, Bedi and Sharma (2006a) held a view of informing schools about the use of QFD is a matter of urgency to improve secondary education.

Bedi and Sharma (2006b) also applied QFD at the collegiate level to the development of business case studies. The study identifies student expectations and looks at the differences between cases that are available and student expectations. Further, the study wanted to find a way to develop case studies that would eliminate the difference between what the students wanted and the case studies that were already available. In essence, students wanted "hot" subjects in real life businesses. The researchers concluded that QFD is useful in finding the voice of students regarding what they prefer in case studies. In fact, they believe QFD should be used with every new class of students because each classes' expectations are unique and case studies should be designed that will capture and hold their interest.

QFD can also benefit in higher education administration. Hafeez and Mazour (2011) defined QFD as "a comprehensive quality governance system" which in this case links customer (student) demands with program and course outcomes, course assessments, and student and faculty course evaluations; the purpose of QFD was to ensure alignment between the various factions to accomplish set program goals as well as university goals and missions. The emphasis of the study was in terms of program cycle. The researchers argued their results identified strengths 
and weaknesses within programming in terms of meeting program goals, program outcomes, and course outcomes.

In summary, QFD has been exercised in a variety of industries, including academic settings. These academic settings range from the elemental setting, that of kindergarten, to the higher education setting. Additionally, in terms of higher education, it has demonstrated use in terms of administration. Its use in terms of designing activities to support the non-academic aspects of a student's life has not been evaluated.

\section{Introducing the American Society for Quality}

The American Society for Quality (ASQ) considers itself to be the "Global Voice for Quality ${ }^{\mathrm{TM}}$ (American Society for Quality [ASQ], 2014), advancing the use of quality methodologies, tools, and concepts to enhance the world's businesses and communities. The organization provides its 76,000 domestic and international individual and organizational members with resources, professional certifications, and training to enhance their ability to meet today's societal and business challenges (ASQ, 2014). It has been in existence for 65 years, with its beginning roots planted just after World War II, with such distinguished members as quality giant Dr. Joseph Juran (ASQ, 2014). ASQ has its roots in engineering, and as such, it advances quality as a notion centered on quantitative decision-making, systematic problem-solving, and standardization. For example, its many certifications include those in terms of Lean manufacturing and Six Sigma, among others.

It is a certified standards developer, providing significant input on the global standards of quality management, environmental management, dependability and reliability, statistics, and social responsibility. It additionally supports the volunteer organizations that develop and approve the well-known ISO standards, which promote consistency and harmony in international business (ASQ, 2014). 
One aspect embraced by ASQ is its support of collegiate student sections. Students, with a faculty advisor, at an Institute of Higher Learning (IHL) can make application to become a student section, with that student section supported not only by its IHL, but also by a local section of ASQ. By working with a local ASQ section, the student section has the opportunity to network with those already practicing in various careers as well as benefit from those individuals' experiences and perspectives. Student sections of ASQ include such institutions as the Ohio State University, University of North Carolina at Charlotte, and the University of Southern California, among others (ASQ, 2014).

With its emphasis on problem-solving, quantitative decision-making, organizational efficiency and effectiveness, and management, an ASQ student section appears to be a worthy endeavor for an IHL. Indeed, as a result of the ASQ foci, the management students at The State University of New York-Fredonia began the formation of its own student section, sponsored by the Erie, Pennsylvania ASQ 0809 Section. The vision of this student section is "Grow Quality, Improve the World." Its mission is "by bridging the gap between academics and workplace, we will model, practice, and explore the Quality Body of Knowledge, thereby improving our club, our communities, and our world, one student at a time." The issue in terms of developing this section to achieve its mission is to determine how it should be structured to meet the needs of its student members so that membership is sustainable, facilitating interaction, while also addressing the needs of potential employers, thereby providing increased marketability and career-growth to those students who participate.

\section{Purpose and Research Questions}

The purpose of this study is to determine if Quality Function Deployment is a credible tool to design a student section of ASQ that will meet not only the desires of the students to facilitate their engagement with the section, but also meet the needs of the potential employers, thereby improving the marketability of the student members. The study is important as 
it seeks to determine the credibility of an established industry tool to foster positive student outcomes, both as a current student and beyond a student's academic career. The following research questions guided the study:

Research Question 1: What student section activities would the prospective ASQ student section members find advantageous and in what priority? These activities constitute the service design aspects of the student section, also known as "the how's" of the design.

Research Question 2: What specific skills are sought by prospective employers of business program graduates? These skills represent the Voice of Customer $(\mathrm{VoC})$ requirements of potential employers, also known as "the what's" in terms of employer needs.

Research Question 3: What are the most advantageous student section activities that will meet the needs of the prospective student members as well as those of future employers? These activities represent the "how much" of an activity is necessary to meet the $\mathrm{VoC}$ requirements.

\section{Methodology}

This case study employed a mixed-methods approach. Quantitative data consisted of responses to Likert-scaled items and the numeric outcomes from the Quality Function Deployment tool, while qualitative data comprised focus group and interview responses.

To answer Research Question 1, "What student section activities would the prospective ASQ student section members find advantageous and in what priority?", a review of the activities conducted by current business school student groups on the campus of The State University of New York-Fredonia was conducted by the research team. The list of those groups is identified in Appendix A: School of Business Student Groups Evaluated for Activities. Those identified activities were collated. A focus group comprised of six senior level business students was presented 
with this slate of activities, and asked to identify other activities they felt might be valuable but not identified as part of the initial review. The activities noted by the focus group were added to the slate of activities. This final menu of activities were then formatted into a Likert-style survey to be administered to a sampling of upper-level business students who might be prospective ASQ student section members to evaluate if the noted activities were indeed considered desirable. The survey is found as Appendix B: Proposed Desired Student Group Activities Survey and Results. The survey was administered via the online survey tool Survey Monkey ${ }^{\mathrm{TM}}$, providing for confidentiality in the survey response process. Here the administrator was the research team and also responsible for the data analysis. The link to the survey was emailed to the students via the college's email system. The link was accompanied by an email that included the purpose of the survey and offered the option for a student not to participate.

Activities would be considered desirable if the survey results demonstrated a preponderance of responses for each positively worded activity statement as "agree" or "strongly agree." If the preponderance of responses reflected ambivalence, "disagree" or "strongly disagree" to the positively worded activity statements, those activities would be removed from the list.

Those activities identified as desirable through the survey to prospective ASQ student section members would be subjected to a weighting process where each activity was assigned a weight value (W) reflective of the importance of the activity on a scale of 1-5 ( $1=$ least important; $5=$ most important). The weighting process was performed by the six member focus group that constructed the menu of desirable activities. The weights (W) were determined by asking each focus group member to weigh the importance of the activity using the 1-5 scale. The resulting measure of central tendency (mean or median) would be calculated for each activity using statistical software to determine the weight used in the analysis. The higher the weight, the more important the focus group found that 
activity to be. The resulting weighted list of activities constitutes "the how's" of the student section design.

By employing the weighting process on design characteristics, this Quality Function Deployment could be considered "reverse," in that typically, the weighting is done on the VoC components. However, by using the weighting process on the design, the student voice is also heard, thereby facilitating the ability to identify activities that would lead to greater participation among the students in the student section.

To answer Research Questions 2, "What specific skills are sought by prospective employers of business program graduates?", available literature was reviewed to determine the top skills desired by prospective employers in terms of graduating business students. The resulting attributes were provided to several management members of local businesses to validate the attributes and provide additional attributes if necessary. The resulting characteristics consistitue "the what's" of the VoC, specifically potential employers. Because these requirements are derived from secondary sources which did not prioritize the characteristics, the weights of the importance of the requirements would be considered uniform.

To answer Research Question 3, "What are the most advantageous student section activities that will meet the needs of the prospective student members as well as those of future employers?", a Quality Function Deployment interrelationship matrix was constructed to understand the relationship between the "what's" and the "how's." This relationship was represented as a Relationship Rating (RR). To determine the RR, the project team used the Delphi technique to provide a value which represented the strength of the relationship between each "what" (each need of the employers) with each "how" (each activity proposed by the ASQ student section). The strength of the relationship was scaled as 1-9 ( $1=$ no relationship; 9 = strongest relationship). Specifically, each project team member anonymously provided a RR for each item; the results were shared among the project team, and this relationship rating assignment process was repeated until consensus was reached. 
The $\mathrm{RR}$ value was multiplied by the $\mathrm{W}$ value of each proposed activity to facilitate the identification of priority activities in terms of potential employer needs. Lastly, a weighted average was calculated for each proposed activity, with the highest weighted averages representing those activities which would address most potential employer needs. For example, referring to Appendix C, Table 1, Quality Function Deployment Interrelationship Matrix for Building a Strong ASQ Student Section, the proposed activity of consulting projects with local businesses was weighted (W) as 5 , which is most important. When evaluating that activity (the how) against team-building (the what), the relationship rating (RR) was determined as the strongest, represented by a value of 9 . Thus, the weighted relationship between team-building and consulting projects is 40 , calculated as the product of the weight and the relationship rating (RR). This calculation process is repeated for the entire column, providing a final weighted average for the proposed activity, calculated as $\Sigma \mathrm{W}^{*} \mathrm{RR}$ for each column $/ \Sigma \mathrm{W}$.

\section{Results}

The results of the study are noted below. These results are considered in terms of each individual research question.

Research Question 1: What student section activities would the prospective ASQ student section members find advantageous and in what priority? These activities and priority represent the design aspects of the ASQ student section; that is, these activities represent "the how's." The student groups associated with the School of Business (Appendix A) were evaluated by the research team with regard to their specific activities. Both consistencies and non-consistencies in activities existed among the groups. In terms of consistent activities, all groups held periodic meetings and sponsored speakers. These consistent activities were added to a menu of activities to be considered by prospective ASQ student section members. A focus group of six senior level business school students considered and determined other possible activities to be evaluated as 
desirable by prospective ASQ student section members. These included plant tours, consulting projects, and technical workshops. All these identified activities were combined into a final menu organized in terms of an on-line survey, found as Appendix B. The survey was administered using Survey Monkey ${ }^{\mathrm{TM}}$ to 80 business students. The students selected were those in the capstone strategic management courses, as these soon-tobe graduating students would have had the most opportunity to explore the available academic student groups within the school of business. The number of responses was $\mathrm{n}=37$.

In terms of the survey, results indicated that consulting projects with local businesses, plant tours, guest speakers, and technical workshops are perceived as highly beneficial to potential student group members. Further, the frequency of general membership meetings should be every other week, as specified by over half of respondents.

Those activities perceived as highly beneficial to potential ASQ student group members were subjected to a weighting process where each activity was assigned a value by the six member focus group that contributed to the menu of desirable activities. The weights (W) were determined by asking each focus group member to weigh the importance of the attribute on a scale of $1-5(1=$ least important; $5=$ most important). The measure of central tendency for each for each activity was determined using statistical software to establish the weight used in the analysis. The median was the measure of central tendency chosen to accommodate any non-normality in the data. The higher the weight, the more important the focus group found that activity to be. The focus group determined consulting projects with local businesses, technical workshops, and plant tours to be the most heavily weighted, with each median value as 5 . Guest speakers and bi-weekly meetings were weighted less important, with median values of 2 and 3 , respectively.

To answer Research Questions 2, What specific skills are sought by prospective employers of business program graduates? The literature review was re-visited, and the key characteristics noted as lacking but 
desired by potential employers were distilled from those studies. The two works, by Peter D. Hart Research, Inc. (2006) and Tugend (2013), suggest that a need exists to develop student skills and abilities in terms of teamwork, problem-solving, prioritization, decision-making, adaptability, and communication (both written and speaking). Further, the ability to apply technical skills is suggested by Tugend (2013). These characteristics were provided to the management members of several local businesses for validation and elaboration.

As a result of this management review function, the notion of technical application was further defined as meaning data analysis, computer software proficiency, and practical applications related to a job. They additionally suggested that prioritization encompass planning and organizational functions as well. Lastly, these individuals also recommended the ability to influence be added. Thus, the $\mathrm{VoC}$ skill and ability requirements were determined to be: teamwork, problem-solving, prioritizing/planning/organizing, communication, decision-making, data analysis, computer software proficiency, practical application, adaptability, and influence. These VoC requirements represent "the what's."

To answer Research Question 3, What are the most advantageous student section activities that will meet the needs of the prospective student members as well as those of future employers? A Quality Function Deployment matrix was constructed using the information from Research Questions 1 and 2. This matrix is found as Appendix C.

The first column of the QFD matrix provides the specific skills identified by potential employers, as derived from the results of Research Question 2. The top two rows of the matrix identifies the student section activities prospective ASQ student section members would find advantageous, along with their weights of importance, as identified in the results of Research Question 1.

A relationship column is provided for each student section activity as it relates to the skills identified by potential employers, represented by the $R R$ value, with the scale of $1-9$ ( 1 = no relationship; 9 = strongest 
relationship). The relationship value was determined by the project team, using the Delphi technique. Specifically, each project team member anonymously provided a RR for each item; the results were shared among the project team, and this relationship rating assignment process was repeated until consensus was reached, for a total of four reiterations. The $\mathrm{RR}$ value was multiplied by the $\mathrm{W}$ value of each proposed activity to facilitate the identification of priority activities in terms of potential employer needs; these weighted RR values are represented within each relationship column. Lastly, a weighted average is presented for each proposed activity, with the highest weighted averages representing those activities which would address most potential employer needs.

Consulting projects with local businesses is a clear priority for this student section, with a weighted average of 17.0. This activity is followed by technical workshops, which provided a weighted average of 10.5. Plant tours and guest speakers resulted in similar weighted averages, with values of 4.5 and 4.2, respectively. The least beneficial activity as provided by the QFD matrix is bi-weekly meetings, with a weighted average of 2.1.

\section{Discussion}

From this study, it appears that Quality Function Deployment is a tool that has utility in identifying key activities a student section of ASQ should pursue that will meet not only the desires of the students to facilitate their engagement with the section, but also meet the needs of the potential employers, thereby improving the marketability of the student members. Specifically, by emphasizing consulting projects and technical workshops, the student section has the greatest opportunity to enhance the skill set desired by potential employers.

In terms of the applicability of the tool itself, the findings are consistent with Moura e Sa and Saraiva (2001), in that the collection of differing perspectives, experiences, and expectations of students in terms of student group activities allowed the research team to develop a menu of design 
characteristics that could be used to answer the future potential employer voices. Further, consistent with Bedi and Sharma (2006b), QFD was useful in discerning which design characteristics should be implemented to better facilitate interaction and market preparedness in terms of student members, allowing for a more efficient use of resources. Moreover, Bedi and Sharma (2006b) also identified that students wanted "hot" subjects in real-life businesses as case studies; overwhelmingly, consulting for local businesses was the most desirable design characteristic in terms of what student members wanted, a consistent desire with that found by Bedi and Sharma (2006b).

The work of Lotkowski et al. (2004) suggests that confidence and motivation play a key role in retention. In terms of the design aspects advanced through the Quality Function Deployment construction, the use of consulting projects and technical workshops are activities that require a great deal of engagement and application; indeed, successful completion of such activities may bolster confidence and achievement motivation within the participating student.

Considering this study in terms of those of Peter D. Hard Research, Inc. study (2006) and Tugend (2013), the use of QFD provided activities that can be clearly linked to achieving or at least enhancing the skill set desired by employers. Indeed, the consulting projects alone were determined to have a positive relationship with all the skills identified. Further, with respect to critical thinking enhancement as advanced by Gellin's (2003) meta-analysis, the implementation of the activities denoted as priority as part of the QFD are those that would require the most interaction among the students, specifically consulting projects and workshops.

\section{Conclusion}

Student groups are certainly a fact of collegiate life, and if these student groups are properly designed, it is likely that they may provide tangible benefits to the student while in his or her academic career and further 


\section{The BRC Academy Journal of Education Vol. 5, No. 1}

into his or her future careers. An important tool to facilitate such a proper design is Quality Function Deployment, a tool used not only within the manufacturing industry, but also within other fields, including academics.

As noted in the literature review, student groups may enhance retention, specifically in terms of provisions of confidence and achievement motivation. Additionally, increased student interaction has been determined to facilitate critical-thinking skills. Critical-thinking skills are foundation to the skill set desired by potential employers of business school graduates. By using QFD to identify student group activities that facilitate student interaction within an established student group, and relating those activities to skills required of potential employees, the likelihood of establishing a beneficial student group is enhanced.

\section{Limitations ANd FURTher StUdy}

This study was limited by several factors. The first factor was the construct of the initial survey to determine the slate of activities to be evaluated. Because the slate was devised by a review of activities which already existed, the survey had limited the ability of the respondent to provide insight into activities that might be desirable but not noted on the survey. A better construct of the survey might be to ask a student what activities they would like a student section to pursue, and then allow the respondents to also determine how important those activities are to them, using a Likert-scale. In this way, a larger, more diverse slate may result, coupled with more insight into what the appropriate importance rating should be. Indeed, it may also be beneficial to ask employers what activities might be helpful in skill development, as these employers have broad experiences which might be useful to develop specific skill sets.

In terms of the skills desired, it would be beneficial to do a broad survey of local employers instead of reliance on secondary research. In this way, a more geographically relevant understanding of desired skills might result. 
Moreover, an inquiry could be made in terms of the importance of these skills from the employers' perspectives, resulting in the ability to do a traditional QFD, as opposed to one which weighted the design aspects. In this case, the study would be repeated; however, no weighting of the design aspects would occur.

Additionally, in terms of limitations, using both a student panel as well as an employer panel to determine the relationship ratings may provide a more accurate representation of the relationship between skill sets and design attributes. For example, because of their unique perspective, employers might be aware of a relationship that is not readily apparent.

The construction of this interrelationship matrix was constrained by time, as the ASQ student branch was recently chartered, and it was imperative to design and implement the branch in a timely fashion. To that end, as the student branch has been implemented, a full HoQ matrix could be constructed, to better understand the relationships among the technical specifications and to determine targets for these specifications.

Lastly, an analysis could be performed to evaluate the career success of ASQ student members who participated in the resulting student group model as compared with students from other student groups which were not designed using QFD. This evaluation could consider such factors as job title, salary, and job performance. The analysis could be conducted from the perspectives of both the students as well as employers, with the results used to evaluate the effectiveness of the QFD process in this application.

\section{REFERENCES}

Akao, Y. (1972). New product development and quality assurance - quality deployment

System (in Japanese). Standardization and Quality Control, 25(4), 7-14. 
Akao, Y. (1994). Development history of quality function deployment. The Customer Driven Approach to Quality Planning and Deployment. Minato, Tokyo 107 Japan: Asian Productivity Organization. p. 339.

American Society for Quality. (2014). We are the global voice of quality. Retrieved from http://asq.org/about-asq/brochure/

Astin, A. W. (1984). Student involvement: A developmental theory for higher education. Journal of College Student Personnel, 25, 297-308.

Bedi, K. \& Sharma, J. (2006a). Benchmarking the quality of secondary education at the micro level and policy imperatives. Social Science Research Network (1-16. U21 Global Working Paper No. 013/2006). Retrieved from http://ssrn.com/abstract $=1606182$.

Bedi, K. \& Sharma, J. (2006b). Quality function deployment in business case studies. Social Science Research Network (1-16. U21 Global Working Paper No. 015/2006). Retrieved from http://ssrn.com/abstract $=1606302$.

Gellin, A. (2003). The effect of undergraduate student involvement on critical thinking: A Meta-analysis of the literature 1992-2000. Fournal of College Student Development, 44(6), 746-762. doi.org/10.1353/ csd.2003.0066

Hafeez, K. \& Mazour, A. (2001). Using quality function deployment as a higher education management and governance tool. Business and Law, 6(1), 31-52. doi:10.5200/1822-9530.2011.02

Lotkowski, V. A., Robbins, S. B., \& Noeth, R. J. (2004). The role of academic and non-academic factors in imporving college retention (ACT Policy Report). ACT Publication. Retrieved from http://files.eric.ed.gov/ fulltext/ED485476.pdf

Moura e Sa, P., \& Saraiva, P. (2001). The development of an ideal kindergarten through concept engineering/quality function deployment. Total Quality Management, 12(3), 365-372. doi.org/10.1080/09544120120034500

Peter D. Hart Research Associates, Inc. (2006). How should colleges prepare students to succeed in today's global economy? Washington: Peter D. Hart Research Associates, Inc. 
QFD Approaches and Techniques. (n.d.). Retrieved January 5, 2016, from http://www.qfdi.org/what_is_qfd/qfd_approaches.html

Ross, P.J. (1998, June). The role of Taguchi methods and design of experiments in QFD. Quality Progress, 41-47.

Siria, D. (2012). An Experiential Learning Activity to Teach the Main Quality Function Deployment Matrix. International fournal of Business, Humanities and Technology, 76-81.

Tsui, L. (1998). Fostering critical thinking in college students: A mixedmethod study of influences inside and outside the classroom. Dissertation Abstracts International, 60(1), p. 1081A.

Tugend, A. (2013). What it takes to make new college graduates employable. Retrieved from http://www.nytimes.com/2013/06/29/your-money/ a-quest-to-make-college-graduates-employable.html?pagewanted= all\&_r $=0$

\section{Citation Information}

Luciano, Nate, Mary Bolo-Blum, Tyler Lokietek, and Lisa M. Walters. "How to Build It So They Come: Using the Interrelationship Quality Function Deployment Matrix to Design a Professional Business Student Club." The BRC Academy fournal of Education 5, no. 1 (2016): 75-96. http://dx.doi.org/10.15239/j.brcacadje.2016.05.01.ja04

\section{Web Appendix}

A web appendix for this paper is available at:

http://dx.doi.org/10.15239/j.brcacadje.2016.05.01.wa04 
